\title{
Seroprevalencia de paratuberculosis bovina mediante la prueba de ELISA urea en rodeos de cría y de leche con sospecha de la enfermedad, localizados en la provincia de Buenos Aires, Argentina
}

\author{
Seroprevalence of bovine paratuberculosis with the urea ELISA test in \\ suspicious breeding and milk herds from Buenos Aires province, Argentina
}

\author{
Alvarado Pinedo María fiorella (i) 1,* , Di Paolo leandro Adrián ${ }^{1,2}$, Sosa Pedro \\ Sebastián ${ }^{1}$, Romero magalí Andrea ${ }^{\mathbb{1} 1}$, Peralta luis María ${ }^{1}$, Costa Enrique Félix ${ }^{2}$, \\ Travería Gabriel Eduardo ${ }^{\text {(i) }} 1$
}

1. Centro de Diagnóstico e Investigaciones Veterinarias (CEDIVE), 2. Cátedra de Patología Médica; Facultad de Ciencias Veterinarias, Universidad Nacional de La Plata, Argentina.

* Correo electrónico de la autora de contacto: falvarado@fcv.unlp.edu.ar

\begin{abstract}
Resumen
Se presentan los resultados obtenidos en 17.747 sueros analizados para el diagnóstico serológico de paratuberculosis bovina, provenientes de 85 rodeos de cría y 5 de leche, ubicados en 14 partidos de la provincia de Buenos Aires. La prueba de ELISA permite diagnosticar esta enfermedad en estadio subclínico, y la incorporación de urea mejora la eficiencia para detectar los anticuerpos específicos contra el Mycobacterium avium subsp. paratuberculosis (MAP). Se estimó la seroprevalencia sobre la base de los resultados obtenidos de animales caracterizados como positivos y sospechosos en la prueba de ELISA urea. Se observó una seroprevalencia individual del 5,5 \% en los rodeos de cría y del 13,6 \% en los rodeos lecheros, siendo la seroprevalencia predial del 78,8 \%. De 425 muestras de heces cultivadas se aisló MAP en el 67,6 \% de los animales positivos, del 52,7 \% de los sospechosos y del 7 \% de los negativos por la prueba de ELISA urea. Mediante estadística bayesiana, el valor predictivo positivo de esta prueba fue de $0,61 \mathrm{y}$ el valor predictivo negativo de 0,93 . Nuestros resultados aportan información actualizada sobre la estimación de la seroprevalencia regional de paratuberculosis bovina, la cual es elevada, y confirma la utilidad de la prueba de ELISA urea, desarrollada localmente, en el diagnóstico y control de la enfermedad.
\end{abstract}

\section{Palabras clave}

Rumiantes, enfermedad de Johne, diagnóstico, ELISA urea

\begin{abstract}
The results of 17.747 bovine serum samples belonging to 85 beef herds and 5 dairy herds from 14 localities of Buenos Aires province are presented. ELISA is the diagnostic test of choice in cattle with subclinical paratuberculosis, and addition of urea in this assay improves the efficiency to detect antibodies against Mycobacterium avium subsp. paratuberculosis (MAP). Seroprevalence was estimated based on positive and suspicious sera to urea ELISA. Individual seroprevalence for beef and dairy herds was $5.5 \%$ and $13.6 \%$, respectively, with an overall herd seroprevalence of $78.8 \%$. In addition, 425 fecal samples were analyzed by microbiological culture. Mycobacterium avium subsp. paratuberculosis was isolated in $67.6 \%$ of positive, $52.7 \%$ of suspicious and $7 \%$ of negative urea ELISA animals. The positive predictive value of urea ELISA was 0.61 , and the negative predictive value was 0.93 using Bayesian statistics. These results are an update to the estimated regional paratuberculosis seroprevalence and confirm the usefulness of urea ELISA in the diagnosis and control of paratuberculosis in cattle.
\end{abstract}

\section{Key words}

Ruminants, Johne's disease, diagnosis, urea ELISA

Fecha de recepción: 31/01/2019

Fecha de revisión: 11/04/2019

Fecha de aprobación: 24/04/2019
ANALECTA VeT 2019; Enero-Junio; 39(1):2-9

Impresa ISSN 03655 14-8 Electrónica ISSN 1514-2590

doi.org/10.24215/15142590eo32 


\section{Introducción}

La paratuberculosis (PTB) es una enfermedad infecciosa crónica de los rumiantes, caracterizada por causar una ileocolitis granulomatosa difusa con compromiso de los linfonodos y vasos linfáticos asociados al íleon y colon. La infección con el Mycobacterium avium subsp. paratuberculosis (MAP) se produce en los bovinos jóvenes vía fecal-oral, por contacto directo con las heces infectantes durante el parto o al ingerir calostro o leche contaminados provenientes de un animal enfermo (Chiodini et al., 1984; Clarke, 1997; Sweeney, 1996). La enfermedad presenta un periodo de incubación prolongado que oscila entre 2 y 8 años, iniciándose con estadios subclínicos que pueden durar varios años, hasta la presentación de signos clínicos y la eliminación de micobacterias en la materia fecal (Whitlock \& Buergelt, 1996). A medida que la enfermedad progresa, los niveles de los títulos de anticuerpos séricos aumentan, coincidiendo con la mayor eliminación de MAP (Barkema et al., 2018; Maroudam et al., 2015). En los bovinos, los signos clínicos son: disminución de la producción láctea, mala condición corporal y diarrea, al principio intermitente y posteriormente continua, la que produce hipoproteinemia con síndrome de malabsorción proteica y pérdida de masa muscular. El cuadro clínico, de varios meses de duración, lleva a la emaciación y muerte. La PTB bovina genera importantes pérdidas económicas, tanto en los rodeos lecheros como en los de carne (Clarke, 1997; Maroudam et al., 2015; OIE, 2018).

En Argentina, Rosenbusch describió por primera vez en los bovinos esta afección en 1932, siendo posteriormente comunicada en 1942 en los ovinos, en 1995 en las cabras y en el 2000 en los ciervos. Se han descrito numerosos casos clínicos compatibles con esta enfermedad, representando una de las principales causas infecciosas de muerte en los bovinos adultos (Costa et al., 2004; Späth et al., 2012). Paolicchi et al. (2003) demostraron una seroprevalencia de $50 \%$ de establecimientos afectados en la provincia de Buenos Aires utilizando la prueba de ELISA. En Uruguay se ha establecido una prevalencia predial del 70,2 \% $\pm 8,1 \%$ (Suanes \& Rubino, 2012) y, en Brasil, también se confirmó la presencia de MAP mediante distintas pruebas diagnósticas (Albuquerque et al., 2017).

En nuestro país, las medidas de control se basan en el diagnóstico y la eliminación de los enfermos, en conjunto con medidas de bioseguridad tendientes a evitar el contacto de los bovinos eliminadores de MAP con los terneros en sus primeras semanas de vida (Alvarado Pinedo, 2015; Gilardoni et al., 2012; Paolicchi et al., 2003).

Las pruebas diagnósticas que se emplean en la actualidad están dirigidas a la detección de MAP de forma directa o a determinar la respuesta inmune del hospedador. La detección del patógeno se puede efectuar a partir del cultivo bacteriológico de muestras de materia fecal, leche, intestino, linfonodos o bien de órganos con lesiones macroscópicas. Las pruebas diagnósticas se comparan con el cultivo bacteriológico que es considerado la prueba de oro o gold standard. El desarrollo de colonias puede observarse en un tiempo no menor a 6 semanas y hasta 6 meses (Whitlock et al., 2000). Para evidenciar la presencia de ADN de MAP existen diversas técnicas moleculares, tales como la PCR convencional, la PCR en tiempo real, la multiplex PCR y las sondas de hibridación (Alinovi et al., 2009; Timms et al., 2015). Estas pruebas se pueden realizar a partir de las muestras clínicas o de los aislamientos, siendo la mayor limitante para su uso masivo los elevados costos. Otra alternativa para el diagnóstico es el hallazgo de lesiones microscópicas características de PTB, con presencia de micobacterias libres o en el interior de macrófagos evidenciables con la coloración de Ziehl Neelsen o mediante inmunohistoquímica (OIE, 2018).

La respuesta inmune es, en un primer momento, de tipo celular, siendo factible su determinación con el uso de la prueba intradérmica con derivado proteico purificado (PPD) aviar, la prueba de linfoproliferación y la cuantificación de gamma interferón (Alvarado Pinedo, 2015; Jungersen et al.,2012; OIE, 2018). Posteriormente la respuesta inmune es de tipo humoral, obteniéndose un diagnóstico serológico indirecto mediante las pruebas de inmunodifusión en gel de agar (AGID) y de ELISA. Sin embargo, de acuerdo con el estadio en el que se encuentre el animal infectado, los resultados pueden variar con cada técnica (Nielsen et al., 2001, 2008; OIE, 2018).

La prueba de ELISA urea se ha utilizado en el diagnóstico serológico de diversas enfermedades para determinar la avidez de los anticuerpos con respecto al antígeno; dicha avidez aumenta con el tiempo después del contacto inicial con el patógeno y se relaciona con la cronicidad de la infección (Iddawela et al., 2015; Lynch et al., 2014). La urea es un agente caotrópico que afecta los enlaces de hidrógeno, desestabilizando las fuerzas hidrófobas que actúan en la unión antígeno-anticuerpo. Las uniones débiles se rompen, quedando unidas las que tienen mayor afinidad funcional o avidez (Fialová et al., 2017). Este efecto es similar al logrado cuando los sueros son absorbidos con otras micobacterias, como Mycobacterium phlei (Di Paolo et al., 2016; OIE, 2018). El objetivo de este trabajo fue estimar la seroprevalencia actualizada de PTB bovina en la provincia de Buenos Aires, utilizando la prueba de ELISA urea con muestras de suero bovino remitidas a nuestro laboratorio.

\section{Materiales y métodos}

\section{Muestras y prueba de ELISA urea}

Se analizaron 17.747 muestras de suero provenientes de 90 establecimientos $(85$ de rodeos 
de cría y 5 de rodeos lecheros) que fueron remitidas al Centro de Diagnóstico e Investigaciones Veterinarias (CEDIVE) para el diagnóstico de PTB bovina, entre los años 2016 y 2018. En la mayoría de los casos las muestras pertenecían a bovinos adultos de rodeos en los cuales se sospechaba la presencia de esta enfermedad. Además, se incluyeron rodeos en los que se realizaba un control sanitario con fines de saneamiento o para la venta de animales como reproductores. Se procesaron muestras provenientes de 14 partidos de la provincia de Buenos Aires, en su mayoría de Chascomús, Magdalena, General Belgrano y Lobos (Fig. 1). La cantidad de muestras y de establecimientos analizados por partido se presentan en la Tabla 1.

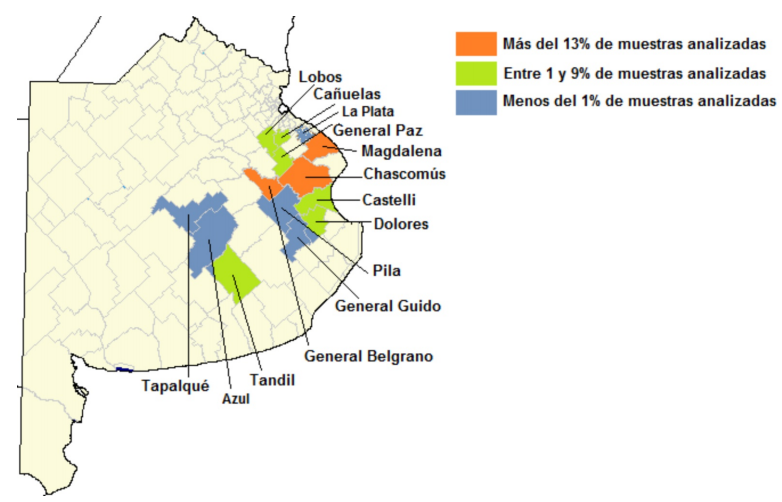

Figura 1. Porcentaje de muestras totales analizadas de cada uno de los partidos que intervinieron en el estudio, para la determinación de la seroprevalencia de paratuberculosis bovina mediante la técnica de ELISA urea.

En la prueba de ELISA urea, se utilizaron placas de 96 pocillos (Microlon®), Greinerbio-one, Kremsmünster, Austria) que se sensibilizaron con $100 \mu \mathrm{l}$ por pocillo de antígeno protoplasmático de MAP con una concentración de $20 \mu \mathrm{g} / \mathrm{ml}$ en solución de carbonato 0,05 M (pH 9,6). Estas placas se colocaron durante la noche en heladera a $4{ }^{\circ} \mathrm{C}$. Al día siguiente, después de lavar 3 veces con una solución tamponada de fosfatos (PBS) con 0,05 \% Tween 20, (ELISA-PBS), se agregaron $100 \mu \mathrm{L}$ de una dilución $1 / 180$ de los sueros control y negativo y de los sueros problema por duplicado. Las placas se incubaron 30 minutos a temperatura ambiente (aproximadamente $20{ }^{\circ} \mathrm{C}$ ). Posteriormente cada placa fue lavada 3 veces con ELISAPBS y se incorporaron $100 \mu \mathrm{l}$ de solución de urea $8 \mathrm{M}$ por pocillo, incubándose a temperatura ambiente durante 4 minutos. A continuación, cada placa fue lavada 3 veces con ELISA-PBS y se agregaron $100 \mu \mathrm{l}$ por pocillo de inmunoglobulina anti-IgG bovina conjugada con peroxidasa (SigmaAldrich $\AA$, Darmstadt, Alemania) con una dilución de 1:5000 en ELISA-PBS. Después de incubar durante 30 minutos a temperatura ambiente, las placas se lavaron 3 veces con ELISA-PBS y posteriormente se agregaron, en cada pocillo, $100 \mu \mathrm{l}$ de solución de revelado. Finalmente se realizó la lectura utilizándose un espectrofotómetro (Lab-systems Multiskan@ Plus, Helsinki, Finlandia) y un filtro de $405 \mathrm{~nm}$ (Di Paolo et al., 2016). Para obtener un valor asociado al porcentaje de positividad de la muestra analizada en relación con los controles (PPRC) se realizó un cálculo a partir de la densidad óptica (DO) promedio obtenida en cada muestra. Dicho cálculo se muestra en la figura 2.

\begin{tabular}{lccc}
\hline \multicolumn{1}{c}{ Partidos } & $\begin{array}{c}\text { Cantidad de } \\
\text { establecimientos }\end{array}$ & $\begin{array}{c}\text { Cantidad de } \\
\text { muestras de suero }\end{array}$ & $\begin{array}{c}\text { Porcentaje de } \\
\text { muestras (\%) }\end{array}$ \\
\hline Azul & 1 & 4 & 0,02 \\
Pila & 1 & 25 & 0,14 \\
Castelli & 5 & 44 & 0,25 \\
Tapalqué & 1 & 54 & 0,30 \\
La Plata & 2 & 62 & 0,35 \\
General Guido & 2 & 124 & 0,70 \\
Dolores & 4 & 181 & 1,02 \\
Tandil & 1 & 300 & 1,69 \\
Cañuelas & 1 & 319 & 1,80 \\
General Paz & 3 & 774 & 4,36 \\
Lobos & 4 & 1480 & 8,34 \\
General Belgrano & 5 & 2459 & 13,86 \\
Magdalena & 16 & 3482 & 19,62 \\
Chascomús & 44 & 8439 & 47,55 \\
\hline \multicolumn{1}{c}{ TOTAL } & $\mathbf{9 0}$ & $\mathbf{1 7 . 7 4 7}$ & $\mathbf{1 0 0}$ \\
\hline
\end{tabular}

Tabla 1. Cantidad de establecimientos y de muestras de suero analizadas en cada partido de la provincia de Buenos Aires, para la determinación de la seroprevalencia de paratuberculosis bovina mediante la técnica de ELISA urea.

Se consideraron como positivos aquellos valores de PPRC iguales o superiores al $70 \%$. Los valores del $60 \%$ al $69 \%$ se informaron como sospechosos. Este protocolo es una modificación del desarrollado previamente por Travería (2003) y el mismo es utilizado en el CEDIVE para el diagnóstico serológico de rutina de PTB bovina.

PPRC $=\frac{(\text { DO } \bar{X} \text { de la muestra }- \text { DO X del control negativo })}{(D O \bar{X} \text { del control positivo }-\mathrm{DO} \bar{X} \text { del control negativo })} \times 100$
PPRC: porcentaje de positividad en relación a los controles
DO: densidad óptica
X: promedio

Figura 2. Fórmula utilizada en el cálculo del porcentaje de positividad de las muestras en relación con los controles (PPRC), utilizando el valor de densidad óptica de cada suero analizado mediante la prueba de ELISA urea.

\section{Análisis bacteriológico de materia fecal}

Para corroborar la eliminación de MAP en las heces mediante el cultivo bacteriológico, se solicitó el envío voluntario de muestras de materia fecal de los animales positivos o sospechosos a la prueba de ELISA urea. Además, se cultivaron 28 muestras de animales que habían resultado negativos. En total se analizaron 425 muestras de materia fecal. Para el cultivo bacteriológico se 
efectuó, durante la noche a $37^{\circ} \mathrm{C}$, la descontaminación de $2 \mathrm{~g}$ por muestra de materia fecal en cloruro de hexadecilpiridinio (Sigma-Aldrich $\AA$, Darmstadt, Alemania) al o,75 \% en agua destilada. Posteriormente se centrifugó a $900 \mathrm{~g}$ durante 30 minutos y al pellet se le adicionó $1 \mathrm{ml}$ de una mezcla de antibióticos conformada por ácido nalidíxico, vancomicina y anfotericina B. Algunas muestras se sembraron en medio de cultivo de Herrold con micobactina (Stabel, 1997) y otras fueron sembradas en un medio de cultivo líquido con el agregado de micobactina, elaborado en el CEDIVE como parte de un trabajo de tesis doctoral (Romero et al., 2018; Whittington et al., 2013). Todas las muestras sembradas se incubaron a $37^{\circ} \mathrm{C}$ entre 1 y 3 meses. El tiempo de desarrollo del cultivo, la morfología de las colonias en los medios sólidos y de las micobacterias al realizar la coloración de Ziehl Neelsen, fueron características microbiológicas que permitieron definir la presencia de MAP en la materia fecal.

\section{Análisis estadístico}

Mediante estadística bayesiana se calcularon los valores predictivos positivo (VPP) y negativo (VPN) de la prueba de ELISA urea (Risso \& Risso, 2017). Para elaborar una curva ROC (Receiver Operating Characteristic) y calcular el área bajo la curva y el punto de corte sugerido de PPRC, se utilizó el sistema estadístico R Core Team (2013) con el paquete pROC (Robinet al., 2011). Para determinar la asociación entre los resultados positivos y sospechosos por la prueba de ELISA urea y el aislamiento de MAP de materia fecal, se utilizó la prueba de chi cuadrado $\left(\mathrm{X}^{2}\right)$ con la corrección de Yates con un nivel de significancia de $\mathrm{p}<0,05$.

\section{Resultados}

Sobre un total de 17.747 muestras analizadas con la prueba de ELISA urea se encontraron 653 animales positivos (3,6 \%), 428 sospechosos $(2,4 \%)$ y 16.666 negativos (94\%). Del total de establecimientos que participaron de este estudio (90) se encontró serología positiva en 71 (78,8 \%) correspondientes a 66 rodeos de cría y a 5 rodeos lecheros. Se observó una seroprevalencia individual a PTB bovina del $5,5 \%$ en los rodeos de cría y del 13,6 \% en los rodeos lecheros. En 19 de los 90 establecimientos estudiados $(21,2 \%)$ se obtuvo resultado negativo, representando un total de 475 muestras de suero, con un promedio de 25 muestras por establecimiento y un rango entre $2 \mathrm{y}$ 45 muestras.

Si bien se indicó efectuar el cultivo de materia fecal de todos los animales que habían resultado positivos o sospechosos a la prueba de ELISA urea, solamente se recibieron en el labo- ratorio 213 heces de bovinos positivos (32,6 \%) y 184 de sospechosos (42,9 \%). Dichas muestras derivaron de 30 establecimientos ubicados en los partidos de Magdalena, Chascomús, General Paz, General Belgrano, La Plata, Tandil, Tapalqué, Castelli y Dolores. Dos de 28 muestras negativas al ELISA urea, provenientes de un rodeo de cría con PTB endémica, resultaron positivas al cultivo. Los resultados totales de los cultivos bacteriológicos realizados se presentan en la tabla 2.

\begin{tabular}{|c|c|c|c|c|}
\hline \multirow[b]{2}{*}{ Partidos } & \multirow{2}{*}{$\begin{array}{c}\text { Cantidad de } \\
\text { establecimientos } \\
\text { que enviaron } \\
\text { muestras de } \\
\text { materia fecal }\end{array}$} & \multicolumn{3}{|c|}{ Aislamientos de MAP de cultivos de materia fecal } \\
\hline & & $\begin{array}{l}\text { Previamente } \\
\text { ELISA urea } \\
\text { positivos }\end{array}$ & $\begin{array}{l}\text { Previamente } \\
\text { ELISA urea } \\
\text { sospechosos }\end{array}$ & $\begin{array}{c}\text { Previamente } \\
\text { ELISA urea } \\
\text { negativos }\end{array}$ \\
\hline Magdalena & 10 & 60 & 34 & 2 \\
\hline Chascomús & 8 & 46 & 30 & 0 \\
\hline General Paz & 3 & 16 & 14 & 0 \\
\hline General Belgrano & 3 & 11 & 16 & 0 \\
\hline La Plata & 2 & 2 & 1 & 0 \\
\hline Tandil & 1 & 4 & 2 & 0 \\
\hline Tapalqué & 1 & 3 & 0 & 0 \\
\hline Castelli & 1 & 1 & 0 & 0 \\
\hline Dolores & 1 & 1 & 0 & 0 \\
\hline TOTAL & 30 & 144 & 97 & 2 \\
\hline $\begin{array}{c}\text { Porcentaje (\%) de } \\
\text { cultivo positivo de } \\
\text { MAP para cada } \\
\text { categoría } \\
\end{array}$ & & 67,6 & $\mathbf{5 2 , 7}$ & 7,1 \\
\hline
\end{tabular}

Tabla 2. Resultados totales de los aislamientos de Mycobacterium avium subespecie paratuberculosis (MAP), a partir de los cultivos de materia fecal de bovinos de algunos partidos de la provincia de Buenos Aires.

Se obtuvo desarrollo de MAP en el 67,6 \% de los cultivos de los animales positivos por la prueba de ELISA urea y en el $52,7 \%$ de los sospechosos, observándose diferencias significativas entre ambos grupos $(\mathrm{p}=0,034)$. Se aisló MAP a partir de materia fecal en el $7 \%$ de las muestras negativas al ELISA urea.

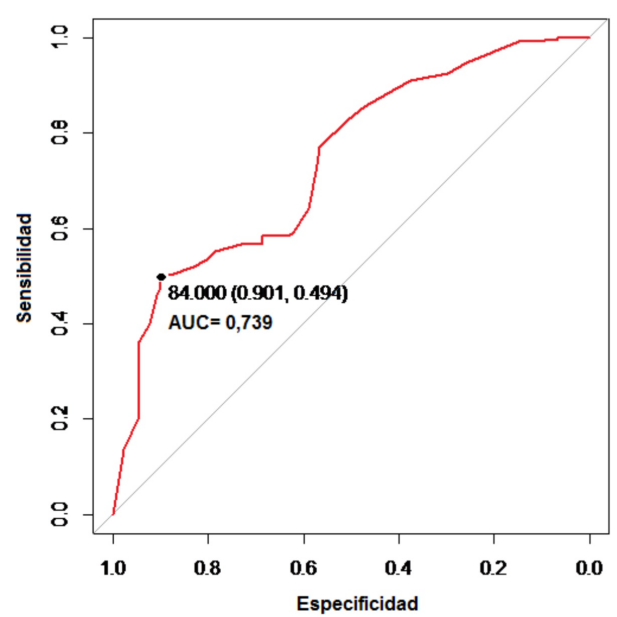

Figura 3. Curva ROC de la prueba de ELISA urea de paratuberculosis. Gráfica de un área bajo la curva (AUC) de 0,739 y una especificidad y sensibilidad del $90 \%$ y $49 \%$, respectivamente. 
De acuerdo con los resultados bacteriológicos obtenidos en las muestras de heces analizadas, la prueba de ELISA urea para detección de PTB bovina presentó una sensibilidad del 49 \% y especificidad del $90 \%$, con un punto de corte sugerido de 84 PPRC para un área bajo la curva de 0,739 (Figura 3), con un VPP de o,61 y un VPN de 0,93 .

\section{Discusión}

En nuestro trabajo se estimó una seroprevalencia individual a PTB bovina del 5,5\% en los rodeos de cría y del $13,6 \%$ en los rodeos lecheros, coincidiendo con los hallazgos descriptos por otros autores en rodeos bovinos en los que la enfermedad se considera endémica (OIE, 2018). La seroprevalencia predial fue del $78,8 \%$ en los establecimientos analizados, observando, en la mayoría de los mismos, animales con signología clínica compatible con PTB bovina. Estos resultados muestran concordancia con un resumen de datos serológicos de esta enfermedad obtenidos durante 25 años en el INTA Balcarce mediante la prueba de ELISA, en donde para rodeos de carne se informó una seroprevalencia predial del $79 \%$ y una individual del 6,3\%. En los rodeos lecheros se informó una seroprevalencia predial del $81 \%$ y una individual del $15,7 \%$, considerándose al sistema productivo lechero como un factor asociado a la enfermedad (Moreno et al., 2017). En los últimos años, en el servicio de diagnóstico que ofrece el CEDIVE, se han incrementado las consultas relacionadas con esta enfermedad, que afecta a rodeos de cría y lecheros y cabañas. Además de las condiciones de manejo propias del sistema lechero, varios factores pueden asociarse a este incremento. Entre estos pueden incluirse los cambios productivos generados por la expansión agrícola, lo que significa que se concentre la cría bovina en sistemas pastoriles de menor superficie. De esa manera, se incrementa la probabilidad de diseminación del MAP.

En la PTB bovina los títulos de anticuerpos séricos son más altos durante la etapa de enfermedad clínica, cuando los animales presentan más lesiones y liberan grandes cantidades de MAP en sus heces y leche (Maroudam et al., 2015). La prueba de ELISA se caracteriza por presentar una mayor sensibilidad en comparación con las técnicas de fijación del complemento y AGID, en cuanto a la detección de animales con enfermedad subclínica y que actúan como portadores (OIE, 2018). Esta técnica es capaz de detectar entre un $30 \%$ y $40 \%$ del ganado vacuno identificado como positivo mediante el cultivo de heces en medio sólido (Whitlock et al., 2000). Esta sensibilidad también depende de la edad del animal, hecho documentado en numerosos artículos que mencionan diferentes porcentajes de sensibilidad, aunque hay estudios en los que se ha calculado que la sensibilidad global estimada para los diferentes grupos de edad es del $15 \%$ (Jubb et al., 2004, Whitlock et al., 2000). La especificidad se encuentra en el rango del 40-100 \% (Nielsen \& Toft, 2008).

En concordancia con esta información, la prueba de ELISA indirecta utilizada en el CEDIVE posee una sensibilidad y especificidad calculada de un $38 \%$ y $97 \%$, respectivamente, presentando mayor eficiencia en animales mayores a los dos años (Travería, 2003). La incorporación de urea, luego de la incubación de los sueros con el antígeno fijado a las placas, le aporta mayor certeza al diagnóstico serológico de la PTB bovina al mejorar sus características operativas. En una enfermedad crónica como la paratuberculosis, los animales que poseen anticuerpos con mayor avidez tienen valores elevados de DO en la prueba de ELISA urea, y estos resultados se pueden asociar a estadios subclínicos o clínicos incipientes que se presentan luego del prolongado periodo de incubación.

En este trabajo se consideraron como positivas las muestras que resultaron con un PPRC $\geq 70 \% \mathrm{y}$, como sospechosas, aquellas con un PPRC entre 60 y $69 \%$, indicándose, en ambos casos, el envío de materia fecal de esos animales para realizar el cultivo bacteriológico y confirmar la infección por MAP. Al analizar los aislamientos de MAP de acuerdo con los resultados previos en la prueba de ELISA urea, obtuvimos 67,6 \% de aislamientos en los positivos y $52,7 \%$ en los sospechosos, con diferencias significativas entre ambos grupos $(\mathrm{p}=0,024)$. Nuestros hallazgos son comparables con los informados por Barkema et al., (2018), pudiéndose correlacionar altos títulos en la prueba de ELISA urea con mayor grado de diseminación de MAP. Con la cantidad de muestras de heces analizadas en este trabajo se obtuvo un $49 \%$ de sensibilidad y un $90 \%$ de especificidad para un punto de corte sugerido de 84 PPRC y un área bajo la curva de 0,739 ; el VPP y el VPN fueron de 0,61 y 0,93 , respectivamente.

Usualmente, el cultivo de materia fecal es capaz de detectar la mayoría de los animales en estadios avanzados de la enfermedad, pero solo identifica algunos animales en las primeras etapas de la infección (Nielsen \& Toft, 2008). La sensibilidad del cultivo fecal es del 70-74\% para el ganado con signos clínicos y del $23-29 \%$ para el ganado con infección subclínica (OIE, 2018). Es sabido que ninguna prueba para el diagnóstico de PTB bovina es el $100 \%$ sensible o específica y estas características operativas son consideradas por nuestro grupo de trabajo al momento de confirmar un diagnóstico y de proponer medidas de control. Los establecimientos que aplican voluntariamente programas de control basándose en el diagnóstico sistematizado y en la eliminación de los animales positivos, logran disminuir la seroprevalencia al cabo de varios años (Alvarado Pinedo, 2015; Moreno et al., 2017; OIE, 2018). 


\section{Conclusiones}

La PTB bovina es una enfermedad infecciosa crónica con un prolongado periodo de incubación, que ocasiona la baja productiva y muerte de los animales enfermos, justificando la existencia de variados métodos diagnósticos que intenten detectar eficientemente la mayor cantidad de animales infectados.

En nuestro país, la PTB bovina se presenta endémicamente y la ausencia de una vacuna aprobada por el SENASA para su aplicación, hace necesaria la utilización de protocolos de control que combinen el uso de técnicas diagnósticas en distintos estadios de la enfermedad.

Aunque las pruebas de ELISA son rápidas y altamente sensibles en animales infectados, en nuestro país aún son de elevado costo, restringiendo su uso a nivel predial si no se utilizan de manera programada y criteriosa.

El uso de la prueba de ELISA urea desarrollada localmente, de menor costo que las actualmente en uso, genera una plataforma promisoria para avanzar en el diseño de las pruebas diagnósticas, tendientes a mejorar las características operativas, adaptándolas a las condiciones epidemiológicas imperantes en la región y a las capacidades de los laboratorios de diagnóstico veterinario.

\section{Agradecimientos}

Los autores agradecen la colaboración de los médicos veterinarios que enviaron las muestras. Este estudio fue financiado parcialmente por el Proyecto de Investigación y Desarrollo (11V220) de la Universidad Nacional de La Plata (UNLP) y por el Fondo para la investigación científica y tecnológica (PICT-2017-2231 Categoría II: Plan Argentina Innovadora 2020). Sosa PS y Romero MA son becarios de la UNLP y de la Comisión de Investigaciones Científicas de la Provincia de Buenos Aires, respectivamente.

\section{Conflicto de intereses}

Todos los autores declaran que no existe conflicto de intereses, incluyendo las relaciones financieras, personales o de otro tipo con otras personas u organizaciones que pudieran influir de manera inapropiada en el trabajo.

\section{Bibliografía}

Alinovi CA, Ward MP, Lin TL, Moore GE, Wu CC. 2009. Real-time PCR, compared to liquid and solid culture media and ELISA, for the detection of Mycobacterium avium ssp. paratuberculosis. Veterinary Microbiology. 136(1-2):177-9.

doi: 10.1016/j.vetmic.2008.10.012
Alvarado Pinedo MF. 2015. Posibilidades diagnósticas de la PPD aviar en la paratuberculosis bovina en animales jóvenes. Tesis de Doctorado en Ciencias Veterinarias, Facultad de Ciencias Veterinarias, Universidad Nacional de La Plata. Disponible en:

http://sedici.unlp.edu.ar/handle/10915/48228

Albuquerque PPF, Santos AS, Souza Neto OL,Kim PC, Cavalcanti, Oliveira JM, Mota RA, Júnior JW. 2017. Detection of Mycobacterium avium subsp. paratuberculosis in bovine milk from the state of Pernambuco, Brazil. Brazilian Journal of Microbiology. 48(1):113-7.

doi: 10.1016/j.bjm.2016.10.010

Barkema HW, Orsel K, Nielsen SS, Koets AP, Rutten VPMG, Bannantine JP, Keefe GP, Kelton DF, Wells SJ, Whittington RJ, Mackintosh CG, Manning EJ, Weber MF, Heuer C, Forde TL, Ritter C, Roche S, Corbett CS, Wolf R, Griebel PJ, Kastelic JP, De Buck J. 2018. Knowledge gaps that hamper prevention and control of Mycobacterium avium subspecies paratuberculosis infection. Transboundary and Emerging Diseases. 65(1):12548. doi: 10.1111/tbed.12723

Chiodini RJ, Van Kruiningen HJ, Merkal RS, Thayer WR Jr, Coutu JA.1984. Characteristics of an unclassified Mycobacterium species isolated from patients with Crohn's disease. Journal of Clinical Microbiology. 20(5): 966-71.

Costa EF, Fazzio LE, Travería GE, Sánchez RO, Alvarado Pinedo MF, Mattioli GA, Otero MM, Chialva M, Romero JR. 2004. Causas de mortalidad y aborto en bovinos. Informe de 1163 casos entre 1986 y 2001 en la provincia de Buenos Aires. Revista de Medicina Veterinaria. 85:16-22.

Clarke CJ. 1997. The pathology and pathogenesis of paratuberculosis in ruminants and other species. Journal of Comparative Pathology. 116(3): 217-61. doi: 10.1016/so021-9975(97)80001-1

Di Paolo LA, Alvarado Pinedo MF, Peralta LM, Romero MA, Travería GE. 2016. Paratuberculosis bovina: diagnóstico serológico con un ELISA urea para intentar categorizar el estadio de la enfermedad. En: XXI Reunión Científico Técnica de la Asociación Argentina de Veterinarios de Laboratorio de Diagnóstico. Jujuy, Argentina, p 79. Disponible en:

http://www.aavld.org.ar/documentos/3MEMORIAS\%20XXI\%20AAVDL\%202016.pdf [Consultado 20/01/2019].

Fialová L, Petráčková M, Kuchař O. 2017. Comparison of different enzyme-linked immunosorbent assay methods for avidity determination of antiphospholipid antibodies. Journal of Clinical Laboratory Analysis. 31(6).

doi: $10.1002 /$ jcla.22121 
Gilardoni LR, Paolicchi FA, Mundo SL. 2012. Bovine paratuberculosis: a review of the advantages and disadvantages of different diagnostic tests. Revista Argentina de Microbiología. 44: 201-15.

Iddawela D, Ehambaram K, Kumarasiri PV, Wijesundera S. 2015. Development and validation of an enzyme linked immunosorbent assay (ELISA) test for the diagnosis of toxoplasmosis in Sri Lanka. Ceylon Medical Journal. 6o(3):82-6. doi: $10.4038 / \mathrm{cmj} . v 60 i 3.8185$

Jubb TF, Sergeant ES, Callinan AP, Galvin J. 2004. Estimate of the sensitivity of an ELISA used to detect Johne's disease in Victorian dairy cattle herds. Australian Veterinary Journal. 82(9):56973 .

Jungersen G, Mikkelsen H, Grell SN. 2012. Use of the johnin PPD interferon-gamma assay in control of bovine paratuberculosis. Veterinary Immunology and Immunopathology. 148(1-2):48-54.

doi: 10.1016/j.vetimm.2011.05.010

Lynch HE, Stewart SM, Kepler TB, Sempowski GD, Alam SM. 2014. Surface plasmon resonance measurements of plasma antibody avidity during primary and secondary responses to anthrax protective antigen. Journal of Immunological Methods.404:1-12. doi: 10.1016/j.jim.2013.11.026

Manual of diagnostic tests and vaccines for terrestrial animals. Chapter 3.1.15. 2018. Disponible en:

http://www.oie.int/fileadmin/Home/eng/Health_ standards/tahm/3.01.15_PARATB\%20.pdf [Consultado 30/01/2019].

Maroudam V, Mohana Subramanian B, Praveen Kumar P, Dhinakar Raj G. 2015. Paratuberculosis: diagnostic methods and their constraints. Journal of Veterinary Science and Technology. 6:259.

doi: 10.4172/2157-7579.1000259

Moreno F, Frade V, Morsella C, Méndez A, Paolicchi F, Späth EJA. 2017. Análisis retrospectivo de paratuberculosis en establecimientos bovinos diagnosticados en INTA EEA Balcarce, Argentina, durante el periodo 1991-2015. En: Memorias de la Sociedad Iberoamericana de Epidemiología Veterinaria y Medicina Preventiva. Valdivia, Chile, p 35. Disponible en:

http://www.sag.cl/sites/default/files/resumenes_ sievmp_valdivia-2017.pdf

[Consultado 14/01/2019].

Nielsen SS, Houe H, Thamsborg SM, Bitsch V. 2001. Comparison of two enzyme-linked immunosorbent assays for serologic diagnosis of paratuberculosis (Johne's disease) in cattle using different subspecies strains of Mycobacterium avium. Journal of Veterinary Diagnostic
Investigation. 13(2):164-6.

doi: 10.1177/104063870101300213

Nielsen SS, Toft N. 2008. Ante mortem diagnosis of paratuberculosis: a review of accuracies of ELISA, interferon-gamma assay and faecal culture techniques. Veterinary Microbiology. 129(3-4): 217-35. doi: 10.1016/j.vetmic.2007.12.011

Paolicchi FA, Zumarraga MJ, Gioffre A, Zamorano P, Morsella C, Verna A, Cataldi A, Alito A, Romano M. 2003. Application of different methods for the diagnosis of paratuberculosis in a dairy cattle herd in Argentina. Journal of Veterinary Medicine. Series B, Infectious Diseases and Veterinary Public Health. 50(1):20-6.

doi: 10.1046/j.1439-0450.2003.00606.x

$\mathrm{R}$ Core Team. 2013. R: A language and environment for statistical computing. $\mathrm{R}$ Foundation for Statistical Computing, Vienna, Austria. Disponible en: http://www.R-project.org/ [Consultado 16/01/2019].

Risso MA, Risso P. 2017. Introducción a la estadística bayesiana: uso de lenguaje $\mathrm{R}$ y Winbugs. La Plata, La Plata, Vuelta a Casa.

Robin X, Turck N, Hainard A, Tiberti N, Lisacek F, Sanchez JC, Müller M. 2011. pROC: an opensource package for $\mathrm{R}$ and $\mathrm{S}+$ to analyze and compare ROC curves. BMC Bioinformatics, 12, p. 77. doi: 10.1186/1471-2105-12-77

Romero M, Alvarado Pinedo M, Moyano R, Peralta L, Sosa P, Santángelo M, Travería G. 2018. Medio de cultivo líquido para el diagnóstico de paratuberculosis bovina. Aplicación y análisis comparativo con el medio de Herrold: resultados preliminares. Analecta Veterinaria. 38(1):50-5. doi: $10.24215 / 15142590 e 025$

Späth EJA, Entrocasso CM, Plorutti F, Manazza JA, Brusca G, Faverín C. 2012. Enfermedades de los bovinos diagnosticadas por veterinarios en el centro-sur de Buenos Aires. Años 2001 a 2007. Boletín técnico $\mathrm{N}^{\circ} 161$, Estación Experimental Agropecuaria Balcarce INTA. Disponible en: http://inta.gob.ar/documentos/enfermedades-delos-bovinos-diagnosticadas-por-veterinarios-en-elcentro-sur-de-buenos-aires.-anos-2001-al-2007 [Consultado 07/01/2019].

Stabel JR. 1997. An improved method for cultivation of Mycobacterium paratuberculosis from bovine fecal samples and comparison to three other methods. Journal of Veterinary Diagnostic Investigation. 9(4):375-80.

doi: 10.1177/104063879700900406

Suanes A, Rubino MC. 2012. Paratuberculosis bovina: diagnóstico, riesgos, impacto económico y 
estrategia de prevención. En: XL Jornadas Uruguayas de Buiatría. Paysandú, Uruguay, p. 6672. Disponible en:

http://centromedicoveterinariopaysandu.com/wpcontent/uploads/2015/o6/Suanes-et-al.-

PARATUBERCULOSIS-BOVINA-DIAGNOSTICORIESGOS-IMPACTO-ECONOMICO-Y-

ESTRATEGIA.-2012.pdf

[Consultado 15/01/2019].

Sweeney RW. 1996. Transmission of paratuberculosis. Veterinary Clinics of North America: Food Animal Practice. 12(2):305-12.

doi: 10.1016/So749-0720(15)30408-4

Timms VJ, Mitchell HM, Neilan BA. 2015. Optimisation of DNA extraction and validation of PCR assays to detect Mycobacterium avium subsp. paratuberculosis. Journal of Microbiological Methods. 112:99-103.

doi: 10.1016/j.mimet.2015.03.016

Travería GE. 2003. Análisis antigénico del Mycobacterium paratuberculosis y diagnóstico de la paratuberculosis bovina mediante enzimoinmunoensayo (ELISA). Tesis de Doctorado en Ciencias
Veterinarias, Facultad de Ciencias Veterinarias, Universidad Nacional de La Plata.

Whittington RJ, Whittington AM, Waldron A, Begg DJ, de Silva K, Purdie AC, Plain KM. 2013. Development and validation of a liquid medium ( $\left.\mathrm{M}_{7} \mathrm{H}_{9} \mathrm{C}\right)$ for routine culture of Mycobacterium avium subsp. paratuberculosis to replace modified Bactec 12B medium. Journal of Clinical Microbiology. 51(12):3993-4000.

doi: 10.1128/JCM.01373-13

Whitlock RH, Wells SJ, Sweeney RW, Van Tiem J. 2000. ELISA and fecal culture for paratuberculosis (Johne's disease): sensitivity and specificity of each method. Veterinary Microbiology. 77(3-4):387-98.

doi: 10.1016/so378-1135(00)00324-2

Whitlock RH, Buergelt C. 1996. Preclinical and clinical manifestations of paratuberculosis (including pathology). Veterinary Clinics of North America: Food Animal Practice. 12(2):345-56. doi: 10.1016/s0749-0720(15)30410-2 